\title{
Training of Teachers through Face-to-Face Contact Mode vs. Online
}

\author{
PK Tulsi ${ }^{1}$, MP Poonia ${ }^{2}$, Anku Bala ${ }^{3}$ \\ ${ }^{1}$ Dean, R\&D, ${ }^{2}$ Director, ${ }^{3} \mathrm{ME}$ student \\ ${ }^{1,2,3}$ National Institute of Technical Teachers Training \& Research, Sector 26, Chandigarh \\ 1pk_tulsi@yahoo.com,'mpppoonia11@gmail.com, ${ }^{3}$ ankubala01@gmail.com,
}

\begin{abstract}
The institute started offering in-service training programmes for technical teachers through the use of information \& communication technologies (ICT)in the year 2012. Initially, Induction Training Programmes were started. The feedback from the participants was quite encouraging and the institute could train almost double the number of teachers during 2012-13. Thus, from the year 2013-14, content matter updating programmes through the use of videoconferencing were also started. During 201314, programmes in the area of Electronics and Communication Engineering were organized both through face-to-face contact mode and online (video conferencing) in which 199 and 319 teachers working in technical institutions participated respectively. Participants' reactions were studied with respect to the various aspects of the programmes namely course contents, competence of faculty, training strategy, outcomes, and utility at workplace. Though a slight decline was observed in the ratings of various aspects of the programmes offered through online but no major differences were observed. A large number of technical teachers could be trained through online inservice training programmes in comparison to programmes organized through regular contact mode.
\end{abstract}

Keyword: In-service training Face-to-face Online

PK Tulsi , Dean, R\&D,

National Institute of Technical Teachers

Training \& Research, Sector 26, Chandigarh

pk_tulsi@yahoo.com

\section{Introduction}

Information and Communication Technologies (ICT) have become a buzzword of the 21 stCentury and are considered the drivers of knowledge societies. The roles of speed and computing power, and broadband connections as envisaged in the report 'The Engineer of 2020'(NAP, 2004) are becoming a reality. The speed and computing power of desktop machines and software enable design and simulation capabilities that make the routine activities of contemporary engineers obsolete, thus freeing them for ever more creative tasks. The world networked with broadband communications, allow huge volumes of information to be transmitted at high data rates for real time collaboration between engineering design centers anywhere, reshaping our perceptions of connectedness, location, and access.

More than 1.2 billion people use Facebook regularly according to numbers released in October 2013 and a recent report by Business Insider reported that 2.7 billion people (almost $40 \%$ of the world population) regularly use social media. The top twenty-fivesocial media platforms worldwide share 6.3 billion accounts among them. Educators, students, alumni, and the general public routinely use social media to share news about scientific and other developments. The impact of these changes in scholarly communication and on the credibility of information remains to be seen, but it is clear that social media has found significant traction in almost every education sector. Social media has now 
proliferated to the point where it spans all ages and demographics. Educators are using them as professional communities of practice, as learning communities, and as a platform to share interesting stories about topics students are studying in class (Johnson, Adams, Estrada, and Freeman, 2014).

ICT have brought a revolution in the way people are educated and trained. There has been potential impact of ICT on and use in teaching -learning, and creative inquiry within the environment of higher education. Flipped classrooms and learning analytics (application of big data in education) are the technologies, which are going to have impact on education with in one to two years (Johnson, Adams, Estrada, and Freeman, 2014). Some of the initiatives undertaken to offer courses online include Coursera, Khan Academy. Edx, Commonwealth Open Learning, and Massive Open Online Courses offered by Universities.

ICT has been used in professional development of teachers in various countries such as Africa, Australia, Canada, China, India, Italy, Japan, Korea, Philippines, Singapore, Tajikistan, UK, USA, etc. Jung (2005) classified various approaches used for teacher training into four namely, ICT as core delivery technology (Virtual High School, USA; Learn Link Project), ICT use as a part of training method (Captured Wisdom, USA; School Administration Technology Integration Resource Project, Canada; and UNICEF's Teacher Talking about Learning), ICT used to facilitate professional development(UK Virtual Teacher Centre, Korea's Education Net, US Teacher Network, World Bank's World Links Programme; School Net, South Africa; Singapore's Clearing House; Sweedish School Net and European School Net).

Some of the initiatives undertaken in South Africa include Connectivity for Educators Development Programme, Uganda; Schools Online, Senegal and Tanzania; School Net in Namibia; Commonwealth of Learning's Southern Africa Teacher Training programme, and Webwise for Africa developed by $\mathrm{BBC}$ in collaboration with Imfundo). A number of problems have been faced in implementation of various projects including lack of infrastructure and unreliable internet access (Unwin, 2004).

A blended approach including workshops, exemplary curriculummaterial and computer mediated communication used to support secondary school teachers of Botswana in the integration of technology in their classroom was found to be a promising arrangement for training teachers in two studies (Voogt, Almekinders, Akker \& Moonen, 2004). Relief International - Schools Online (RISOL) School Connectivity Project in Tajikistan successfully used the Cascade approach to reach teachers in over 20 secondary schools spread throughout the mountainous country. Following the initial one-week intensive workshop, RI-SOL staff traveled monthly to the schools to meet with trainees and communicated daily via online chat to help them develop a teacher professional development (TPD) plan and practice communication, technology, and lesson planning skills (Goible and Burns, 2005).

Various modes, face-to-face classroom interaction, the modular type (in implementing distance education in-service training), tele-movie and the Computer-Assisted Instruction (in CD-ROM format, not Online) either singly or in combinations have been used for in-service training of teachers by The Normal Philippines University. UPNISMED organizes Continuing Science Education for Teachers via Television on Saturday and Sunday (Pontiveros, 2001).

In India too, attempts have been made to provide in-service training to teachers through ICT such as radio programmers, TV programmes, EDUSAT programmes for school and college teachers, Gyandarshan and Gyanvani channels for teachers of higher education, National Programme on Technology Enhanced Learning (NPTEL), online courses by universities and institutions of higher learning and NITTTR Chandigarh Technology Enabled Learning (NCTEL).

A few studies have been carried out to determine the potential of ICT for teacher training in Indian context. Interactive Video Technology was used in a seven-day training programme for primary teachers in the state of Karnataka. The responses of teachers and trainers indicated considerable potential of technology where large number of teachers was to be trained (Maheshwari and Raina, 1998). Indian Institute of Technology, Bombay used both satellite (EDUSAT) and internet technology to reach out to a large number of college teachers through thirty remote centres. About $93 \%$ of the teachers were introduced first time to new teaching aids and technology (MOODLE and clicker). Survey findings indicated that $43 \%$ of the respondents said that the overall experience was excellent and $52 \%$ rated the 
experience as good. $90 \%$ of the teachers agreed that they would adopt the teaching material and methodology in their teaching (Kannan \& Narayanan, 2010).Course evaluation of in-service training programmes offered online indicated that a large number of technical teachers could be trained with the help of ICT. $95 \%$ of the participants rated their experience of participating in the programme between good to excellent with an overall rating of 4.08 on a five-point scale. Major problems encountered during the programmes were low bandwidth internet, frequent breaking- up of link during the initial programmes, poor quality of audio and video reception and power failure at times leading to missing a part of the programme by participants (Tulsi, Poonia and Pattnaik, 2013).

Capper (2000) reported the major findings of three case studies conducted with the support of World Bank Info Dev Programme intended to document various models of teacher training and technology. Armenia's The Three Pomegranite Network (3PN), a global online learning programme connected Armenian students and teachers through out the world by engaging them in collaborative project based learning. All of the training of teachers was done through project's website. Both students and teachers were able to successfully implement the project activities as intended. He concluded that web based guidance/training for teachers could be effective and perhaps sufficient to help teachers implement online, collaborative problem based activities with their students. It led to the conclusion that this could be the cost effective approach to training teachers than faceto-face particularly when large number of teachers were involved. The two case studies in China focused on use of television as one of the delivery modes to provide in-service training to teachers. Both studies found that TV programmes were seldom used and teachers preferred direct review of the material due to pressure of passing an examination at the end of each year of coursework. It was found that teachers lived quite a distance from the study centres and did not have time to go to study centres. Video tapes were expensive for teachers. National Institute of Education, Singapore was able to integrate the use of information technology in their pre-service teacher training programme due to availability of adequate resources and clear direction from the top.

The use of distance education and ICT led to increasing the availability and access to professional development of rural teachers through setting up of
Teaching Learning Resource Centres. Professional development became resource rich, teachers were able to access educational television channels, Radio and Television University and Classroom on the Air and teachers could access websites of other teachers and participate in discussions. It helped teachers in implementation of new teaching ideas and approaches (Robinson, 2008).

Mathe (2013) did a comparative study of the inservice training in Korea and Australia. He reported that Training Teachers for the Future Project in Australia used bottom up approach and created commitment and collaboration across universities and other higher education institutions. The modalities used included face to face meeting, telephone conference and social platform-blogs. The project focused on complex integration of technologies on the basis of TPACK i.e. technological, pedagogical and content knowledge. High quality digital resources were developed and project also led to development of sustainable professional networks and national standards for technology.

On the basis of the findings of the studies stated above, it can be concluded that ICT have a great potential in reaching the unreached and increasing access to professional development, it is possible to train a large number of teachers with the help of ICT, ICT provide variety of options or alternatives to teachers to further enhance their capabilities and it helps in bringing changes in teaching-learning and in turn enhancing student learning.

\section{Technical Education System in India}

Technical education system in India comprises of 81 centrally funded institutes of National importance including Indian Institutes of Technology (IITs), Indian Institutes of Management (IIMs), National Institutes of Technology(NITs), Indian Institutes of Information Technology (IIITs), Indian Institutes of Science and Research (IISERs), National Institutes of Technical Teachers' Training and Research (NITTTRs). 10326 degree level and 4276diploma level technical institutions offer courses in Engineering and Technology, Applied Arts and Crafts, Architecture \& Town Planning, Hotel Management and Catering Technology, Management, Master's in Computer Application, Pharmacy etc. The intake capacity of these institutions is 2.54 and 1.30 million respectively. However, quality of technical education is a major concern with stakeholders. 
Serious concerns have been expressed regarding the quality of curriculum, instructional processes, evaluation, technical graduates from these institutions, quality of linkages with world of work and feedback. The employability of the technical graduates is declining (NASSCOM \&McKinsey Global Institute, 2005; Aspiring Minds Assessment Pvt. Ltd., 2010 \& 2014 and Blom and Saike, 2011) and majority of the students are leaving their core branches of engineering and entering into IT and ITeS sector. It has been invariably expressed that graduates from technical institutions lack generic skills and higher order cognitive skills such as ability to analyze, evaluate and create as well as the practical skills.

The responsibility of providing quality instruction and maximizing student learningliesprimarilyon teachers. Most of the teachers working in technical institutions in India are fresh graduates and they lack exposure to field practices and pedagogy. Knowledge explosion leading to emergence of new disciplines, concepts, principles $\&$ theories and decline in the shelf values of degrees, rapidly changing technology and modern communication revolution, all demand that teachers must update and upgrade their knowledge on a continuous basis. The faculty of technical institutions requires knowledge and skills in their own areas of specialization (hard skills), training in educational technology (pedagogy/andragogy), industrial exposure and a host of soft skills to build excellence in technical education. Staff development, professional development and career development, all the three, are essential to develop needed competence among teachers. Government, technical institutions, technical universities and faculty themselves have realized the importance of continuous improvement through faculty development or in-service training programmes. Realizing the need to improve quality of teachers and teaching, Government of India has launched Mission Teacher \& Teaching during Twelfth Five Year Plan (2012-17) with the sole objective of improving quality of higher education.

\section{National Institute of Technical Teachers Training and Research (NITTTR), Chandigarh}

NITTTR (earlier known as Technical Teachers' Training Institute) is one of the four institutes in country and was set up in 1967 by the then Ministry of Education (now Ministry of Human Resource Development, MHRD) Government of India to bring qualitative improvement in technical education especially in the polytechnic education system in the country. The institute caters to the training needs of about 4500 technical institutions in the northern region of the country and only about 5000 teachers were trained annually through face-to-face contact programmes. The institute started offering in-service training programmes through video conferencing since September 2012, primarily to meet the mandate given by Ministry of Human resource Development (MHRD) and to increase the reach of institute programmes and the number of teachers trained annually. Initially, only Induction Training Programmes were organized but from the year 201314 , content matter updating training programmes were also started through video conferencing and use of social media (Google Hangout). Fig.1shows the number of teachers trained through during 20032015.

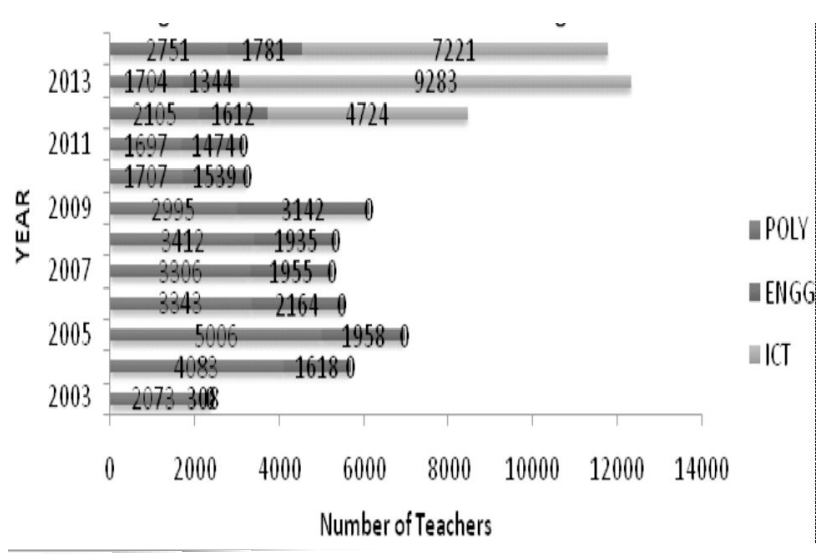

Fig. 1 : Number of Teachers Trained During 2003-2015

\section{Sample}

For the present study, data from one of the departmentsi.e. Department of Electronics \& Communication Engineering has been taken. The department organized Embedded System, Wireless \& Mobile Communication, MATLAB \& Its Applications, DSP \& Its Applications, VLSI Design, Introduction to System Designing, Introduction to Embedded System, GSM, 2G to 3G Communication, GSM to GPRS, FPGA Based Digital System Design, GSM \& CDMA and Wireless LAN through face to face contact mode and Optical Fiber Communication, Computer Network and VLSI Design online. 199 teachers were trained through face-to-face contact mode and 399 teachers online in the year 2013-14. Participants'reactions towards various aspects of the programme were taken on a five point rating scale at the end of each programme. 


\section{Major Findings}

Participants' $(\mathrm{N}=598)$ reactions were taken on various aspects of the programme namely, Course contents: selection of course contents (SCC), sequence and organization of contents (SOC), relevance of contents (ROC)\&actual coverage of contents (ACC); Competence of faculty: soft skills of coordinator (SSCo), presentation skills of coordinator (PSCo) and presentation skills of other faculty (PSOF) ); Training Strategy: use of variety of training techniques(UVTT), quality of training materials(QTM), motivational input to make training interesting(MICI), inputs from industry/field experts (IIE)and punctuality maintained in conducting the programme (PCP); Outcomes: extent of expectations fulfilled(EEM) and utility of programme at work place(UWP)) and Overall Rating to the programme (OR).Fig.2shows the average ratings assigned to various aspects of the programmes organized face-toface $(\mathrm{F} 2 \mathrm{~F})$ contact mode and online

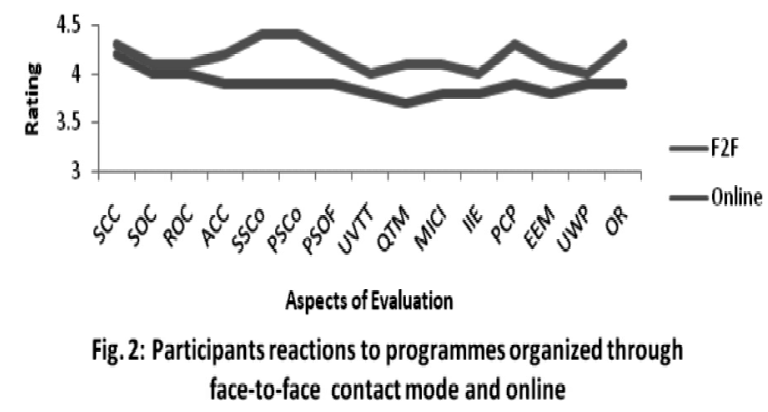

From the Fig. 2, it is quite evident that the participants' reactions towards the various aspects of the programmes have shown slight decline in case of programmes offered online. The average ratings to various aspects in case of programmes offered through face-to-face contact mode ranged between 4(use of variety of techniques) and 4.4 (soft skills and competence of coordinator) while in case of programmes offered online, the average ratings ranged between 3.7 (quality of training materials) and 4.2(selection of course contents).Soft skills of coordinator do matter in face to face contact based programmes but have limited role to play in online programmes. The reasons for slight decline could possibly be due to the fact that trainers, in case of online programmes, were restricted in the use of various training techniques, participation of participants was limited due to hesitation on the part of participants and limited practical work and practice provided to participants.
Some of the aspects that need attention, as per the participants of the programmes, include: better networking facility, clarity of power point presentations, inclusion of basic concepts, more emphasis on practical work, two way communication, and better quality audio \& video. The issue of low bandwidth in case of networked centres led to poor quality of audio \& video. Experts/faculty experienced difficulty in demonstrating practical aspects due to limitation of size of screen and various icons of the softwares. Participants also opined that power point presentations can be sent to them and more programmes can be organized online.

In addition, it was observed that where ever the top leadership was committed and took interest in the programmes, teachers took more interest and were serious in attending the programmes and the assigned tasks. Training cost was reduced in terms of TA/DA to participants, honorarium to experts, and TA/DA to faculty.

\section{Conclusions}

On the basis of the findings, it can be concluded that in-service training programmes can be organized online with the help of social media, help in increasing the reach of institute programmes, large number of teachers can be trained through the use of technology without dislocating them from their workplaces, teachersare equally satisfied with such programmes and training cost per participant can be reduced. However, the problems as they exist in terms of networking and low bandwidth, proper infrastructure and facilities need to be created at networked centres to improve the quality of reception of the online programmes.

\section{References}

Andreas Blom, Saeki Hiroshi (2011). Employability and Skill Set of Newly Graduated Engineers in India. The World B a k South A s i a RegionEducationTeam.http:/wwwwds.worldbank.o $\mathrm{rg} /$ servlet/WDSContentServer/WDSP/IB/2011/25/0 00158349_20110425112950/Rendered/PDF/WPS56 40.pdf

Aspiring Minds(2010), National Employability Study IT/ITeS Sector: Key findings and Intervention Indicators. Aspiring Minds Assessment Pvt. Ltd.

A. N. Maheshwari, V(1998), In-service Training of Primary Teachers Through Interactive Video Technology: An Indian Experience International Review of Education, 1998, 44:1, pp 
87101.http://link.springer.com/search?facetauthor $=\% 22 \mathrm{~A} .+\mathrm{N} .+$ Maheshwari\%22

Bernadette Robinson (2008), Using Distance Education and ICT to improve access, equity and quality in rural teachers professional development in Western China. International Review of Research in Open and distance Learning, 9:1, 2008, 1-15

Edmond Gaible, Mary Burns (2005), Using Technology to Train Teachers: Appropriate Uses of ICT for Teacher Professional Development in Developing Countries. Washington, DC: infoDev / Wor $1 \mathrm{~d}$ B a n k. A va i l a b 1 e a t: http://www.infodev.org/en/Publication.13.html

Fabian C. Ontiveros(2001), Pre-Service and InService Teacher Education in the Philippines. http://gauge.u-gakugei.ac.jp/ 09/2001

Insung. Jung (2005), ICT-Pedagogy Integration in Teacher Training: Application Cases Worldwide. Journal of Educational Technology \&Society, 8:2, 92104.

Joanne Capper (2000), Teacher training and technology: An overview of case studies and lessons learnt. TechKnowLogia, November/December, 2000. http://www.techknowlogia.org/TKL_Articles/PDF/1 95.pdf

Joke Voogt, MarinusAlmekinders,Jan van den Akker, Bert Moonen (2004), A 'blended' in-service arrangement for classroom technology integration: impacts on teachers and students. ElsevierScience.2005.http://doc.utwente.nl/67974/
Kalpana Kannan, K.Narayanan(2010), ICT enabled teacher training for Human capital formation: A study of I I T B o m b a y i n i t a t i ve. http://www.hss.iitb.ac.in/FGKS_IITB_2010/papers/ Kalpana.pdf

L. Johnson, S. Adams Becker, V. Estrada, A. Freeman(2014), NMC Horizon Report: 2014 Higher Education Edition. Austin, Texas: The New Media Con sortiu m. w w w. n m c.org/n m chorizon $\square \square \square \square \square \square \square$

Melinda Mathew(2013),ICT in Teacher Training: A Comparative Analysis of ICT Policies for Education South Korea and Australia. Assignment for the course International and Comparative Education.

NAP (2004),'The Engineer of 2020'. The National Academic Press Washington: USA. www.nap.edu

NASSCOM-McKinsey Report (2005), Extending India's Leadership of the Global IT andBPOIndustries.www.mckinsey.com/global_locat ions/asia/india/en/our..

P.K.Tulsi, M.P.Poonia, S.S. Pattnaik. (2013), Training of Technical Teachers through Integration of Information \& CommunicationTechnology in India. The Asian Conference on Education 2013, Official Conference Proceedings.

Tim Unwin. (2004). Towards a framework for the use of ICT in Teacher Training in Africa. Special issue of Open Learning: The Journal of Open and Distance Ed u c a tion o n O p e n e a r n i n g inLessDevelopedCountries.www.gg.rhul.ac.uk/ict4d /ict tt africa.pdf 